\title{
ANALYSIS OF CHINESE POLICY OF TUITION-FREE NORMAL COLLEGE STUDENTS: PURPOSE, CONTENT AND EFFECT
}

\author{
Xue Yuankang \\ Faculty of Education, Beijing Normal University (China)
}

\begin{abstract}
The Chinese policy of tuition-free normal college students implemented in 2007 was replaced by the policy of "state-financed" (also tuition-free) normal college students in 2018. Thus it is necessary to review the process of the policy of tuition-free normal college students, the purpose of this education policy is to alleviate the social problems of the imbalance in the distribution of teachers, the shortage and low quality of rural teachers. The main policy content includes recruit students mainly from poor central and western provinces, and they must teach in their home province for at least 10 years after graduation. The process of policy implementation includes policy propaganda, policy decomposition, organization and material preparation, policy experiment and comprehensive implementation, coordination and monitoring. This article mainly uses document research and interview methods, plus analysis of relevant statistical data, and found that, the policy has basically achieved the expected purpose, but there are still many problems in the implementation process, such as the tuition-free normal college students' studying motivation is weak, the low satisfaction of the tuition-free normal college students with the policy content, and graduates have a relatively higher percentage of defaults of contract.
\end{abstract}

Keywords: Chinese education policy, policy of tuition-free normal college students, analysis of education policy, tuition-free normal college students, imbalance in the distribution of teachers.

\section{Introduction}

In May 2007, the Chinese ministry of education and other four departments promulgated the "Implementation Measures for Free Education of Normal Students Directly Under the Ministry of Education (Trial)", and then the policy of free education for normal students began to be implemented. By July 2018, when it was replaced by the policy of "state-financed" (also tuition-free) normal college students, the policy had been implemented for 11 years. Policy alternatives means the end of a policy (Chen Zhenming, 2003). After the end of a policy, a comprehensive and systematic summary of it will help people to comprehensively review all aspects of the policy, However, since the end of the free education policy for normal students in 2018, there has been little review paper in this area by domestic scholars, so this paper intends to analyze the purpose, content and effect of this policy.

\section{Policy problems and policy objectives}

\subsection{Policy problems}

The policy of free education for normal students is mainly aimed at the social problems of unbalanced distribution of teachers, lack of rural teachers and low quality of rural teachers. For a long time, Chinese educational resources show a huge difference between urban and rural areas and between different regions. Rural-urban disparity and east-west disparity featured Chinese educational landscape. A large part of this disparity in educational resources are due to the differences in their teacher resources.

The imbalance of teacher team is first manifested in the surplus of urban teachers and the shortage of rural teachers. For example, in 2005, a special supervision and inspection of 109 primary and secondary schools in 15 counties of Jiangxi, Henan, Hainan, Guangxi, Sichuan and Qinghai by the state education supervision group showed that, the phenomenon of urban teachers overstaffed and rural teachers understaffed is common in the six provinces (National education supervision group, 2006). secondly, it also shows that the number of teachers in the eastern region is surplus while there are still a certain number of informal teachers (mainly called "supply teacher", which outside the establishment) in the western region, the regional differences are still obvious. the third problem is the low quality of teachers in some rural areas. According to a survey, there are still more than 167,000 rural teachers who do not meet the national requirements as a qualified teacher in 2010 (Wu Yue, 2010).

In this context, the problem of non-benign flow of rural teachers makes the problem more serious. Many studies have pointed out that there has been a serious loss of teachers in rural primary and secondary schools in central and western China. For example, A scholar take two towns in, Kaifeng City, 
Henan Province as research cases and find that from 2002 to 2005, 118 teachers flowed out of these two areas, with a loss rate of $11.2 \%$ (Ma Lili, 2007).

Therefore, the key to solve the imbalance of teachers lies in the supplement of rural teachers, especially to reduce the flow rate of rural teachers. The free education policy for normal students is one of a series of policies aimed to solve this problem. Among them, the provisions directly related to this problem are: the free normal graduates want to work in urban schools should first teach in rural compulsory education schools for at least two years. In this way, the state can directly supply teachers to rural areas through policies and regulations.

\subsection{Policy purpose}

In 2007, the policy text defined the purpose of free education policy for normal students as "to form a strong atmosphere of respecting teachers and valuing education, to make education the most respected cause in the whole society; to cultivate a large number of excellent teachers; to promote the education quality of teachers, to encourage more outstanding young people to be lifelong educators." but in fact, the purpose of the policy is not so simple and clear. The policy text clearly points out that, first of all, free normal students should not only promise to be engaged in primary and secondary education for more than ten years after graduation, but also those who work in urban schools should first serve as teachers in rural compulsory education schools for at least two years. Secondly, free normal students should return to their hometown to teach after graduation. It can be seen that the policy of free education for normal students is not only to cultivate a large number of excellent teachers, but also to promote the balance of educational resources, especially teachers' resources.

In academic community, some researchers pointed out that the main purpose of this policy is to promote the reform process of rural primary and secondary school teachers, and improve the overall quality of rural teachers (Lu Keliang et al, 2009). Even in the eyes of the media, free education for normal students is also aimed at achieving education equity by alleviating the shortage of rural teachers (Liu Hongxia, 2018). at the press conference held by the Ministry of education in September 2011, $\mathrm{Xu}$ Tao, then director of the department of normal education of the Ministry of education, also made clear that the focus of the free education policy for normal students was to "train backbone teachers for rural schools" (Henan Provincial Department of Education, 2012).

Therefore, this paper holds that there are two main purposes of the free education policy for normal students, namely, first, to promote the balanced development of teachers. The second is to train a large number of excellent teachers, and promote the quality of teachers through the reform of teacher education in some famous normal universities.

\section{Policy implementation and policy effect}

\subsection{Policy implementation}

The process of policy implementation mainly includes policy propaganda, policy decomposition, material preparation, organizational preparation, coordination and monitoring (Chen Zhenming, 2003).

3.1.1. Policy propaganda. In order to carry out the policy effectively, we must first unify people's ideological understanding. Policy propaganda is an effective means to achieve this goal. The policy implementation institutions involved in the free education policy for normal students mainly include the education department, personnel department and other relevant government departments and normal universities.

The publicity of the government departments is mainly through the government working conference, press conference and relevant media. For example, at the "two sessions" in March 2007, Premier Wen Jiabao announced in the government work report that the state will implement the policy of free education for normal students this year. (Wen Jiabao, 2007) Later on May 18, 2007, the Ministry of Education held a press conference to introduce relevant information.

The publicity of universities is mainly reflected in the enrollment process. For example, Shi Ningzhong, President of Northeast Normal University at that time, said that, Northeast Normal University sent 21 publicity groups to some key middle schools in Jilin Province to publicize the significance and policies of free education for normal students, in order to recruit a batch of good graduates. (Northeast Normal University, 2007)

3.1.2. Policy decomposition. Generally speaking, the launch of a policy usually only points out the basic direction to achieve the policy objectives. Therefore, it is necessary to decompose the policy objectives under these basic principles. The policy of free education for normal students involves many stakeholders, and the implementation process is very complex. The policy of free education for normal students can be broken down into enrollment policy, training policy, enter post-graduate school policy and employment policy. 
In terms of enrollment policy, in May 2007, the Ministry of Education issued Circular of the Ministry of education of the people's Republic of China on the enrollment of free education normal students in normal universities directly under the Ministry of Education. which requires the provincial college enrollment committee and the normal universities directly under the Ministry of Education to seriously formulate enrollment implementation measures. The provincial departments take Fujian Province as an example. The Education Department of Fujian Province requires each city's education bureau to make the enrollment of free education normal students in advance. The accepted free education normal students must go to the city's education bureau where the students are from before entering university to sign the free normal student education agreement issued by the provincial education department (Fujian Provincial Department of Education,2007). In other aspects, the steps of policy decomposition are similar. First, the central government issues their policies, and then the provinces and universities make their specific policies and implement them.

3.1.3. Material preparation. Material preparation is the economic basis to ensure the implementation of the policy. The material preparation of the free education policy for normal students is mainly the financial guarantee of the central government for the normal university implementing the policy. In December 2007, the general office of the Ministry of Education issued the notice of the general office of the Ministry of education on arranging the free education funds for normal students in 2007, (general office of the Ministry of education, 2007) which clarified the subsidy project, subsidy standard and allocation time of the free education funds for normal students in 2007. For the six normal universities directly under the Ministry, special funds from the central government shall be arranged. The allocation standard of free education funds for normal students is 12000 yuan per student per year.

3.1.4. Organization preparation. Organizational preparation is the guarantee mechanism for the implementation of policies, and the performance of organizational functions directly determines the degree of the realization of policy objectives. which including the establishment of policy implementation agencies, the establishment of necessary rules and regulations, etc.

In the central government departments, the State Council is responsible for the overall planning of the free education policy for normal students, with the Ministry of education as the main executive body. The Ministry of education is responsible for holding a conference on the implementation of free education for normal students every year, guiding universities to prepare the free normal student education agreement with the nature of administrative contract (Zhang Nan, 2011) and other policy texts.

In the provincial government departments, take Henan Province as an example, the work of free normal university graduates is coordinated by the relevant provincial government departments, and a working group composed of education, human resources and social security, finance and other departments, which is responsible for the formulation and implementation of employment policy.

As for the normal university, take Southwest University as an example, it first establishes the organization responsible for policy implement, including the establishment of the leading group for free education for normal students. Secondly, it carried out the overall mobilization and deployment. In May 2007, it held the implementation meeting of free education for normal students. Finally, a series of management rules and regulations such as "Southwest University's opinions on the implementation of free education for normal students in 2007" have been issued, which provides systemic guarantee for the full implementation of free education for normal students (Chen Shijian et al, 2007).

3.1.5. Coordination and monitoring. The coordination and monitoring of policies run through the whole process of policy implementation, which is the necessary condition to ensure the full implementation of policies. In the central government, the coordination work is coordinated by the State Council. The Ministry of education, the Ministry of human resources and social security, the Ministry of Finance and other four departments are responsible for the specific implementation. For example, on the eve of the first free normal students' graduation in 2010, the Ministry of education, together with other three departments, held a free normal graduates' employment conference in Beijing.

In the provincial government, the work coordination mechanism of free normal students is as mentioned above. Taking Shandong Province as an example, the provincial education administrative department, human resources and social security department, financial department and other provincial government departments, as well as the municipal and county governments perform their respective duties, and coordinate with each other in the implementation of the free education policy for normal students. The monitoring is mainly focused on the free normal graduates' employment work, (Wang Zhichao,2013) for example, in terms of employment work, the provinces specially emphasized the responsibility of the local government where the students come from, and arranged the inspection mechanism for related work. Some provinces also clearly proposed to give "notice of criticism" (such as Guangdong Province) to areas where the arrangement of free normal graduates' employment is not effective, "reduce the number of free normal students enrolled" (such as Jilin Province) and other penalties. 


\subsection{Policy effect}

The policy effect is the influence and effect on the object and environment after the implementation of the policy. From the perspective of stakeholders, the implementation effect of the policy can be more clearly understood its impact on different groups.

3.2.1. Policy target groups. The target group of free education for normal students is the students who at a growing age. This group is the most important direct stakeholders. Analyzing the impact of the policy on the target group can intuitively understand the effect of the policy.

First, policy content satisfaction. A scholar surveyed some free normal graduates from six normal universities found that in terms of the acceptance of the policy, $20 \%$ of the free normal graduates did not support the policy very much. In terms of the goal orientation of the free normal student policy, more than $30 \%$ of the students do not want to become a primary and secondary school teacher, and $44.7 \%$ of the respondents say they do not want to teach in primary schools for a long time. The goal orientation of the free normal student policy is not recognized by most graduates (Wu Peng et al, 2016).

Second, policy implementation satisfaction. From the perspective of free normal students, the satisfaction of policy implementation is mainly reflected in the training of normal universities and the learning program of free normal students. A survey of Beijing Normal University shows that $62.4 \%$ of the students are very satisfied with the teaching measures taken by normal universities (Yao Yun et al, 2009), but a survey of the learning motivation of free normal students shows that $39.1 \%$ of the students feel that they have no motivation to learn during their undergraduate period (Bai Beiyou, 2016).

Third, the degree of achievement of policy objectives. The premise of achieving the policy objectives is that all the free normal students can teach in the central and western regions after graduation, so the breach of contract is an important indicator to test the degree of achieving the policy objectives. Zhang Lijun found that only $48.11 \%$ of the students said they would not breach the contract (Zhang Lijun et al, 2010). From 2012 to 2016, six normal universities directly under the Ministry of education trained 52000 free normal graduates, with a contract employment rate of $96.5 \%$, of which $90.3 \%$ went to primary and secondary schools in the central and western regions to teach (Jin Xiaoyan, 2017).

3.2.2. Policy implementation groups (normal universities). First, the training situation of free normal students. Many empirical studies have shown that some free normal students lie in the lack of learning motivation and unclear learning objectives (Jia Zhi et al, 2012). there are also institutional reasons such as the lack of corresponding competition and elimination mechanism, the free normal students don't have to worry about work after graduation. It can be seen from this that the implementation effect of the free policy for normal students does not completely depend on the implementation of the training program, the unreasonable employment policy may lead to deviation of the implementation.

Second, the employment situation of graduates. The balance of teachers is one of the important goals of the free education policy. In the subordinate Normal University, the report on the employment situation of graduates of Shanxi Normal University (2013) shows that the number of free normal graduates in 2013 is 2866 , all of whom are employed. The proportion of employment in the west is higher, reaching $71.39 \%$; the proportion of employment in the middle is $18.49 \% ; 10.12 \%$ of them are employed in the East; $22.40 \%, 38.24 \%$ and $39.36 \%$ of them are employed in provincial capital, prefecture level city and county level respectively (Shaanxi Normal University, 2014).

The free normal graduates from subordinate normal universities is mainly went to the central and western regions, but the proportion of these students teach in the county-level schools is low. Many empirical studies also proved this point, that is to say, the policy of free normal students in the subordinate normal university mainly solves the problem of imbalance teacher distribution between the eastern and western regions. In contrast, the main goals of free education for local normal universities are to solve the shortage of teachers in rural areas, such as Xinjiang (Wu Liang, 2014).

\section{Summary}

The free education policy for normal students began to be piloted in six subordinate normal universities in 2007, gradually implemented in local areas since 2010, and replaced by the policy of "state-financed" normal college students in 2018. The policy aims to solve the imbalance of teachers and the shortage of rural teachers, aiming to cultivate a large number of excellent teachers.

This paper finds that the results of the policy are quite in line with expectations, in which the free education policy for normal students under the Ministry mainly solves the problem of unbalanced regional distribution of teachers, and the free education policy for local normal students mainly solves the problem of lack of teachers in local villages. But at the same time, the process of policy implementation is also unsatisfactory, such as the learning motivation of free normal students is not strong, and a certain proportion of free normal graduates' default. There are many reasons for these problems, such as the student's lack of understanding of the policy content and the inflexible employment policy. 


\section{References}

(April 10, 2014). Annual report on employment quality of graduates of Shaanxi Normal University in 2013. Retrieved May 30, 2019, from http://www.snnu.edu.cn/info/1085/19603.htm.

(December 22, 2007). Notice of the general office of the ministry of education on arranging free education funds for normal students in 2007. Retrieved June 6, 2019, from http://www.moe.gov.cn/srcsite/a10/s7011/200712/t20071222_.html.

(February 20, 2012). Henan Provincial Department of Education: the reality and expectation of free normal students teaching in rural areas. Retrieved May 28, 2019, from http://www.haedu.gov.cn/2012/02/20/1329746875562.html.

(June 27, 2007). Fujian Provincial Department of Education: Notice on enrollment of free education normal students in normal universities directly under the Ministry of Education. Retrieved June 6, 2019, from http://jyt.fujian.gov.cn/xxgk/zywj/200706/t20070627.htm.

(May 18, 2007). Implement free education for normal students: Northeast Normal University pays attention to strengthening teaching practice. Retrieved June 6, 2019, from http://www.china.com.cn/txt/2007-05/18/content_htm.

Beiyou B. (2016). Research on policy evaluation of free education for normal students. (Doctoral dissertation Shaanxi Normal University, Xi'an, China). Retrieved from http://xueshu.baidu.com/usercenter/paper/show?paperid=ebf881164a9ac58610893f757d642179\&s ite=xueshu_se\&hitarticle $=1$.

Hongxia L. (2008, August 18). "Free" to "public expense" to keep normal students is the fundamental. China industry and economic news, p.001.

Jiabao, W. (March 5, 2007). Normal university directly under the Ministry of education will implement free education for normal students this year. Retrieved June 6, 2019, from http://www.china.com.cn/2007li anghui/2007-03/05/content_7905302.html.

Jin Xiaoyan. (2007 September 3). Outstanding achievements in teacher team building. Guangming Daily, $\mathrm{p} 2$.

Keliang L., \& Qiongfang L. (2009). A survey of the first free normal university students' study and living conditions. Chinese adult education, (01), 91-92.

Liang W. (2014). Difficulties and solutions of free normal students' training in local normal universities. Teacher Education Forum, 27 (05), 5-9.

Lijun Z., \& Jie Y. (2010). Investigation on the development of the first free normal students. University (Academic Edition), (07), 62-75.

Lili M. (2007). A study on the current situation and Countermeasures of teacher turnover in rural primary and secondary schools in central and Western China. Journal of Chongqing Polytechnic, (03), 49-51.

Nan Z. (2011). The legal nature of free normal student education agreement. Education review, (04), 28-30. Chinese Ministry of Education. (2006). Bulletin of the special supervision and inspection of the national education supervision group on the management of primary and secondary school principals and teachers in six provinces (autonomous regions). Beijing: National Education Supervision Group. Retrieved from old.moe.gov.cn//publicfiles/business/htmlfiles/moe/moe_768/200601/13795.html.

Peng W., \& Weidong F. (2016). Reasons for low policy recognition of free normal university graduates and countermeasures. Education and economy, (01), 63-67.

Shijian C., Xun P., \&Yonghua Z. (2007). Implementation of free education for normal students in Southwest University.University (Research and evaluation), (10), 5-8.

Yue W. (2010). Analysis of education policy: Taking the "special post plan" of rural school teachers as an example. Education theory and practice, 30 (01), 28-30.

Yun Y., \&Xiaowei D. (2009). A survey on the implementation of free education policy for normal students. Education research and experiment, (1), 45-50.

Zhenming C. (2013). Policy Science: Introduction to Public Policy Analysis.Beijing: Renmin University of China Press.

Zhi J., Lei T., \& Guoni Y. (2012). A survey of learning motivation and learning of free normal students. Teacher education research, 24 (02), 69-74.

Zhichao W. (2013). A follow-up study on the implementation of free education policy for normal students. Changchun: Jilin People's publishing house. 